\title{
Are Cognitive, Affective, and Eudaimonic Dimensions of Subjective Well-Being Differently Related to Consumption? Evidence from Japan
}

\author{
Tetsuya Tsurumi ${ }^{1}$ (D) $\cdot$ Rintaro Yamaguchi $^{1} \cdot$ Kazuki Kagohashi $^{1} \cdot$ Shunsuke Managi ${ }^{1}$
}

Accepted: 12 October 2020 / Published online: 26 October 2020

(c) The Author(s) 2020

\begin{abstract}
In this study, we investigate the relationship between consumption and subjective wellbeing (SWB). There is clear evidence in the literature that the income-SWB relationship depends on the SWB measure, but the reasons are not fully clear yet; however, the main reason may be related to consumption because most income is used for that. This study is the first to examine directly whether the consumption-SWB relationship differs between affective, cognitive, and eudaimonic SWB measures. We adopt the following four SWB indices: life satisfaction, the Cantril ladder, affect balance, and eudaimonia. In addition, on the consumption side, we consider both material and relational consumption. Nonparametric analysis of our uniquely collected survey results in Japan suggests that total consumption contributes to cognitive measures of SWB and eudaimonia, while there is a certain threshold for affective measures. However, once material versus relational consumption is considered in total consumption, we find that relational consumption contributes to any SWB measure without clear upper bounds, while material consumption contributes to all SWB measures only to certain thresholds. Our results also show that the marginal effects of total consumption, material consumption, and relational consumption on cognitive measures of SWB and eudaimonia are greater than on affective measures. In addition, our results show that the marginal effects of relational consumption tend to be greater than those of material consumption for all SWB indices. Based on the findings, we expect relational consumption to be key for improving well-being.
\end{abstract}

Keywords Subjective well-being $\cdot$ Cognitive measure $\cdot$ Affective measure $\cdot$ Eudaimonia Consumption $\cdot$ Relational consumption $\cdot$ Material consumption

Electronic supplementary material The online version of this article (https://doi.org/10.1007/s1090 2-020-00327-4) contains supplementary material, which is available to authorized users.

Tetsuya Tsurumi

tsurumi@nanzan-u.ac.jp

1 Nanzan University, Nagoya, Aichi, Japan 


\section{Introduction}

\subsection{Income-SWB Relationship}

The paradox between income growth and a corresponding rise in reported subjective well-being (SWB) was identified nearly half a century ago in the seminal work of Easterlin (1974). Since then, there has been much debate about the income-SWB relationship. In his more recent evaluation of the topic, Easterlin (2001) concludes that people with higher incomes, on average, are happier than those with lower incomes; although there is a point of diminishing returns, he suggests that as income rises, people increase their material aspirations, which in turn undermines the potential gains of SWB.

As Clark et al.'s (2008) literature review suggests, the general consensus of previous studies is in line with Easterlin's conclusion that income indeed raises happiness, with diminishing returns to income. Some of those studies include analyses using cross-sectional survey data from one country with or without standard demographic controls (e.g. Graham and Pettinato 2002; Blanchflower and Oswald 2007). Other studies use panel data from one country to control for unobserved individual fixed effects (e.g., Winkelmann and Winkelmann 1998; Ferrer-i-Carbonell 2005; Gardner and Oswald 2007). Yet other studies employ macroeconomic variables, including GDP, to control for country fixed effects (e.g. Di Tella et al. 2003; Helliwell 2003; Leigh and Wolfers 2006).

However, the findings in the literature seem to be highly dependent on what a given study actually measures for SWB (see, e.g. Deaton 2008; Stevenson and Wolfers 2008; Diener et al. 2010; Kahneman and Deaton 2010). According to the Organisation for Economic Co-operation and Development (OECD 2013), there are three main types of indexes that measure SWB: those related to "life evaluation," in which an individual evaluates his or her own life experiences or life as a whole (e.g., life satisfaction and the Cantril ladder); those related to "emotional well-being" (affect balance), which measure an individual's feelings or psychological state at or during a certain point or period in time; and those related to the concept of "eudaimonia," which capture an individual's goal orientation or sense of life purpose. It is important to note that there is some debate about whether these two types of life evaluation indexes-life satisfaction and the Cantril ladder-represent the same thing (Helliwell et al. 2012). For example, the Cantril ladder produces a wider distribution of responses (Office for National Statistics 2011) and is more strongly correlated with income than other life evaluation indexes. Diener et al. (2010) show that income seems to be positively correlated with cognitive measures of SWB but not with affective measures. Similarly, Kahneman and Deaton (2010) demonstrate that in the United States, there might be an income threshold for emotional well-being of around US\$75,000, after which emotional well-being does not increase, while there might not be such an income threshold for life evaluation. Jebb et al. (2018) statistically identify points of income satiation for other countries. The authors apply spline regression models to global data from the Gallup World Poll and, controlling for demographic factors, find that satiation occurs at US\$95,000 for life evaluation and US\$60,000 to US\$75,000 for emotional well-being. In addition, they find substantial variation across world regions, with satiation occurring later in wealthier regions; for some countries, incomes beyond satiation are associated with lower life evaluations. Thus, there is clear evidence that the income-SWB relationship depends on the SWB measure, but the reasons are not yet fully clear. Given that most income is used for consumption, a main reason may be related to consumption. The current 
study is the first to examine directly whether the consumption-SWB relationship differs between affective, cognitive, and eudaimonic SWB measures.

\subsection{Definition of SWB}

The broader concept of SWB has drawn much attention (Benjamin et al. 2012); however, as mentioned, our interest lies in the difference between affective, cognitive, and eudaimonic SWB measures. In this subsection, to contextualize the affective, cognitive, and eudaimonic SWB measures adopted in our study, we review the big picture of the evolving massive body of literature, chiefly drawing on a book-length treatment by Sirgy (2012).

Many researchers distinguish between cognitive and affective aspects of SWB (Campbell 1976; McKennell 1978; Andrews and McKennell 1980; McKennell and Andrews 1980; Organ and Near 1985; Brief and Roberson 1989; Crooker and Near 1995; Kahneman 2011). How do affective and cognitive measures of SWB relate to each other? Most studies regard life satisfaction as self-evaluation of happiness (Diener 1984; Veenhoven 1984a, 1984b; Veenhoven and Coworkers 1994). In other words, life satisfaction is viewed as a "cognitive" conceptualization of happiness or SWB and may involve judgments of fulfillment of an individual's needs, goals, and wishes (Cantril 1965; Andrews and Withey 1976; Campbell 1976; Michalos 1980; Diener 1984). Diener et al. (1985) define life satisfaction as a cognitive judgmental process dependent upon a comparison of one's circumstances with what is thought to be an appropriate standard. One of the most well-known cognitive measures is the Cantril ladder (Cantril 1965), comprised of steps 0 at the bottom to 10 at the top, in which respondents are asked which step of the ladder represents where each feels that he or she stands at the present time. Meanwhile, positive and negative emotions are referred to as affective measures (Ahuvia and Friedman 1998).

However, that is not the end of the story, as a large body of the literature emphasizes the relative nature of SWB. In the cognitive evaluation of happiness, an individual must surely assess his or her situation relative to some benchmark or reference, such as his or her own life in the past, the lives of surrounding people, a global standard, or a shifting "best possible life for you" standard that moves upward with rising living standards (Deaton, 2008). ${ }^{1}$ In addition, Ahuvia and Friedman (1998) suggest that SWB includes both affective and cognitive components and that the cognitive and affective elements of SWB tend to be correlated. They state that "the cognitive judgement that one's life is a failure is likely to result in negative affect and the reverse for more flattering cognitions."

Another question arises: can eudaimonic well-being be treated equally with affective and cognitive measures of SWB? While Kesebir and Diener (2009) consider that eudaimonic well-being and other SWB measures are sufficiently close, Vitterso et al. (2010) argue that they are theoretically distinct, as the cybernetic principles underlying them are different. Goal attainment in hedonic well-being reflects homeostatic balance, which

\footnotetext{
1 Specifically, when the standard of living is low to begin with, an increase in income is likely to lead people to feel satisfied with the increase; however, when the standard of living is high, the increase in income is not likely to positively raise an individual's evaluation of his or her standard of living. This relative nature of life evaluation also applies across individuals and is related to the so-called relative income effect in that people indeed compare themselves to others, which serves to dampen the correlation between income and happiness (Sirgy 2012). A similar effect is well recognized in studies of consumption and happiness, and has been given various labels, such as conspicuous consumption, social consumption, peer pressure, and keeping up with the Joneses, to name a few.
} 
reflects a state of happiness. By contrast, lack of goal attainment reflects a state of disequilibrium that induces feelings of interest, curiosity, challenge, and task absorption. The latter may be reflective of eudaimonic well-being.

This points to the need to treat eudaimonic well-being separately from the dichotomy between affective and cognitive measures. Peterson et al. (2005) develop a measure based on Seligman's theory of authentic happiness, which seems to capture the three major dimensions of happiness: hedonic well-being, life satisfaction, and eudaimonia (Sirgy 2012). ${ }^{2}$

Thus, in the current study, we adopt the following four SWB indexes: life satisfaction (cognitive), the Cantril ladder (cognitive), affect balance (affective), and eudaimonia. ${ }^{3}$ Affect balance can be classified with hedonic happiness (well-being) and affective measures, and short-term well-being (Kozma et al. 1992; Parducci 1995; Sumner 1996; Kahneman 1999). By contrast, life satisfaction, the Cantril ladder, and eudaimonia can be classified with eudaimonic well-being (happiness), cognitive measures (Phillips 2006; Kesebir and Diener 2009; Vitterso et al. 2010), and long-term well-being. ${ }^{4}$

\subsection{Consumption-SWB Relationship}

In studies on SWB, in the tradition of the Easterlin paradox, income is often utilized as the yardstick (Kahneman and Deaton 2010). At a macro level, national income and GDP are frequently discussed with the implicit assumption that they are relevant to welfare. However, microeconomic theory starts with the assumption that individuals maximize utility derived from consumption, not from income. Income and consumption have equivalent impact on welfare only in a static, one-good setting in which individuals do not save at all. Moreover, recent studies stress other contributors to individual well-being, such as social capital, leisure, and inequality (e.g., Stiglitz et al. 2010; Benjamin et al. 2014; Tsurumi and Managi 2017).

This point rationalizes our focus in the current study: we consider the association of SWB with consumption instead of income. The literature on the total consumption-SWB relationship is huge, including studies by Guillen-Royo (2008), Headey et al. (2008), Zimmermann (2014), and Noll and Weick (2015). Headey et al. (2008) show somewhat contradictory results: the total consumption-life satisfaction relationship is positive for the United Kingdom but negative for Hungary. It is possible that people may become dissatisfied and insecure once their consumption level rises for a given level of income and wealth. There are other potential channels that make this relationship seem inconsistent. For example, Guillen-Royo (2008) suggests that in the Peruvian corridor, consumption has a meaning beyond mere satisfaction of basic needs, such as status concerns regarding the reference

\footnotetext{
${ }^{2}$ Similarly, Haybron (2000) classifies three philosophical components of happiness (psychological, prudential, and perfectionist), which Sirgy (2012) argues are largely in line with Seligman's (2002) distinction (the pleasant life, the engaged life, and the meaningful life, respectively).

3 For details, see Cantril (1965), Andrews and Withey (1976), Campbell (1976), Campbell et al. (1976), McKennell (1978), Andrews and McKennell (1980), McKennell and Andrews (1980), Michalos (1980), Diener (1984), Diener et al. (1985), Veenhoven (1984a, 1984b, 1991), Organ and Near (1985), Brief and Roberson (1989), Veenhoven and Coworkers (1994) and Crooker and Near (1995).

4 Meanwhile, reflecting the findings of Haybron (2000), Seligman (2002), and Peterson et al. (2005), affect balance can be classified with hedonic well-being (psychological happiness or pleasant life), life satisfaction and the Cantril ladder can be classified with prudential happiness (the engaged life), and eudaimonia can be classified with perfectionist happiness (the meaningful life).
} 
group, the pleasure of consuming, providing for household basics, and the expectation of escaping social marginalization. Likewise, Zimmermann (2014) shows total consumption in the United States is significantly associated with SWB, but only via certain consumption goods, such as experiential and conspicuous expenses.

Moreover, we treat both total consumption and different subtypes of consumption, as the latter may yield different marginal utilities. One category worth studying is relational consumption, through which people feel connected to others and which often entails both leisure and social capital investment. ${ }^{5}$ Examples include consumption involving interactions with family members, friends, and acquaintances, such as sending a gift, having dinner, or traveling in social groups. DeLeire and Kalil (2010), Noll and Weick (2015), and Zhang and Xiong (2015) study the effect of relational consumption of leisure on SWB. However, relational consumption has a deeper meaning than that of a mere leisure activity. Like economic conditions, social capital exerts a significantly positive influence on SWB relative to other factors (Frey and Stutzer 2002; Bjørnskov 2003; Di Tella et al. 2003; Becchetti et al. 2008; Bruni and Stanca 2008). Relatedly, Kasser and Sheldon (2002) examine consumption practices during Christmas and consumer well-being. They show that consumers report higher levels of happiness when they consider family and religious experiences as important but lower levels of happiness when they consider spending money and buying gifts as important. In addition, by utilizing social capital indicators that measure trust in others and citizen participation, Bjørnskov (2003) shows that social capital affects happiness to a greater degree than income, at least in developed countries. Although our concept of relational consumption in this study does not necessarily entail social capital investment, we can conjecture that relational consumption may exert a correspondingly powerful influence on SWB. ${ }^{6}$

A related but separate class of consumption worth clarifying here is experiential consumption, such as vacations and concert tickets, as opposed to material consumption or the possession of goods (Van Boven and Gilovich 2003; Dunn and Weidman 2015; Gilovich et al. 2015). We focus on consumption involving interactions with other people and not experiential consumption per se. Relational and experiential consumption share common traits: dining out with family, for example, is an activity that falls under both categories. Eating out alone, by contrast, is an example of experiential consumption but not relational consumption. ${ }^{7}$

\footnotetext{
5 The concept of relational goods, although not irrelevant, is not directly significant to our argument. Relational goods usually refer to goods whose consumption raises utility just because others consume them as well (cf., Donat 2010). Social consumption, another similar but distinct term, refers to consumption behavior influenced by that of some reference individual. For example, Sunstein and Ullmann-Margalit (2001) point out that individuals' consumption choices are affected by the perceived consumption choices of others. Dasgupta (2014) presents an analysis in which social consumption, whether competitive or conforming, involves externality.

${ }^{6}$ Concern for the well-being of others leads us to the principle of altruism. Studies have shown that altruism elevates SWB as well as social capital (e.g., Meier and Stutzer 2008; Binder and Freytag 2013; Gimenez-Nadal and Molina 2015). Thus, even if expenditure is the same, a greater share of altruistic consumption may be linked with heightened SWB. Hedonic adaptation does not apply to all types of activities and outcomes (Frank 1999; Frey and Stutzer 2003). People do not seem to adapt their utility evaluation in the case of outcomes that are related to so-called intrinsic motivations, as opposed to extrinsic motivations (Welsch and kühling 2009). The things that we most easily become accustomed to and are most likely to take for granted are our material possessions, while other experiences-such as the time that we spend with family and friends-do not compare in the same way (Layard 2005).

${ }^{7}$ Experiential consumption can also lead to negative outcomes (Pandelaere 2016), because people do not always obtain positive outcomes from experiences (e.g., stressful transportation, a disappointing concert, and poor service at a beach resort) (Nicolao et al. 2009). In addition, if people engage in experiential con-
} 
Based on literature review, Dolan et al. (2008) suggest that the effect of material wellbeing on SWB is not linear but rather diminishes with higher levels of material well-being; this is similar to the economic concept of diminishing marginal utility. Diminishing marginal effects are also revealed in empirical studies. For example, Gokdemir (2015) reports that, in Turkey, only the consumption of durable goods is correlated with life satisfaction. DeLeire and Kalil (2010) analyze US data for nine consumption categories and show that, of all the categories measured, only one, leisure, is positively correlated with SWB. Zhang and Xiong (2015) employ 77 consumption categories and 13 SWB indicators to examine the relationship between consumption and SWB in Japan. A notable finding of their study is the particularly strong correlation between relational consumption and SWB. Dumludag (2015) analyzes countries at different stages of development in Europe and shows that the relationship between life satisfaction and each consumption category varies in accordance with the development stage. Relatedly, Pandelaere (2016) reviews studies on experiential versus material purchases and suggests that even though many studies find an advantage for experiential purchases, this effect does not occur for materialists. He states that materialists do not benefit more from material than from experiential consumption owing to unrealistic expectations.

The literature outlined in this section has not clarified how the choice of SWB indexes affects the consumption-SWB relationship, which is not sufficiently discussed in the extant literature. In addition, on the consumption side, we consider both material and relational consumption.

The rest of the paper is organized as follows. Section 2 describes the theoretical model; Sect. 3 presents the empirical models and data; Sect. 4 describes the estimation results; and Sect. 5 discusses the findings, presents the conclusion, and indicates opportunities for further research.

\section{Theoretical Model}

We first simplify the argument by equating utility with SWB. Although some previous works stress the distinction between the two (e.g., Glaeser et al. 2016), for the purpose of comparison with the literature using SWB indexes, we adopt SWB as the proxy of utility in the current study. Kahneman and Krueger (2006) mention that acceptance of self-reported measures of well-being, subject to the many caveats required by subjective measurement, could have a profound impact on economics and that the currently available results suggest that those interested in maximizing social welfare should shift their attention from increasing consumption opportunities to increasing social contacts. Given our literature review in subsection 1.3, we start from individual utility as a function of material consumption and relational consumption. We assume that a representative agent's instantaneous utility at $t$ depends on material consumption $\left(C_{1}\right)$ and relational consumption $\left(C_{2}\right)$ :

Footnote 7 (continued)

sumption for nonautonomous reasons, it does not necessarily affect their SWB (Zhang et al. 2013). What matters for SWB is what types of experience the respondent is going through (Bhattacharjee and Mogilner 2014; Kumar and Gilovich 2016). Psychological gain from experiential consumption is emphasized if the experience is shared with others as opposed to occurring in isolation (Caprariello and Reis 2013). 


$$
U\left(C_{1}(t), C_{2}(t)\right)
$$

where in theory, marginal utilities are positive with regard to both types of consumption, namely, $U_{1}>0$ and $U_{2}>0$.

Our literature review in subsection 1.2 suggests that there are broadly three types of well-being: affective, cognitive, and eudaimonic. Some studies also suggest there are two types of psychological well-being: short- and long-term. Kozma et al. (1992) theorize that happiness is a direct function of two psychological states, one short term and the other long term. The short-term state is an affective state that involves positive and negative affects mostly influenced by environmental factors. The long-term state is also an affective state involving both positive and negative affects but is dispositional and less affected by environmental factors than the short-term state. Parducci (1995) and Kahneman (1999) argue that affective measures of SWB of any time period are a conceptual summation of these separate hedonic values, positive and negative, divided by the duration of that period. By contrast, global assessments that people make when asked to rate their overall happiness are cognitive measures of SWB, because they are based on an individual's thoughts and judgments about major elements of his or her life. Sumner (1996) argues that well-being must be based on global evaluations of life (i.e., a long-term construct).

One way to incorporate all of these types of well-being into the model would be to hypothesize that affective or emotional well-being may capture the effects of spur-of-themoment consumption or short-term consumption, while cognitive well-being or the evaluation of life may better reflect consumption in the long term or for future ends. Thus, we interpret affective versus cognitive well-being as corresponding to the maximization of instantaneous versus intertemporal utility. The latter can be written as

$$
V(t)=\int_{t}^{\infty} U\left(C_{1}(\tau), C_{2}(\tau)\right) e^{-\delta(\tau-t)} d \tau,
$$

where $\delta>0$ is the pure rate of time preference. It follows that the marginal effects of consumption of type $j \in(1,2)$ on SWB would correspond to marginal utility $\left(\partial U / \partial C_{j}\right)$ versus marginal intertemporal utility $\left(\partial V / \partial C_{j}\right)$. For the present purpose, it is sufficient to note that in general, they should be expected to differ. ${ }^{8}$ As mentioned in subsection 1.2 , there is a question of whether eudaimonic well-being can be treated equally with affective and cognitive measures of SWB.

From the literature on the relationship between income and SWB, which we show in subsection 1.1, we expect cognitive measures and eudaimonia to be more correlated with consumption than affective measures. However, the relationship between income and SWB may depend on how income is used. The literature review in subsection 1.3 suggests that, concerning relational consumption and material consumption, relational consumption is expected to be more correlated with SWB than material consumption. However, regarding the relationship between total consumption and SWB, we cannot expect correlation between total consumption and SWB, because it may depend on the share of relational consumption and material consumption in total consumption; this would then become an empirical issue.

\footnotetext{
${ }^{8}$ An extended model of the optimal economy incorporating social capital is developed in Appendix.
} 


\section{Estimation Strategy}

\subsection{Empirical Model}

As we attempt to examine the consumption-SWB relationship, we are essentially interested in the partial derivatives of instantaneous or intertemporal utility. For this empirical purpose, a reduced form of $U$ or $V$ from the prior section would be as follows:

$$
S W B_{i}^{k}=\gamma_{1}+f\left(\text { consumption }_{i}\right)+\sum_{j} \alpha_{j} X_{i j}+\epsilon_{1}
$$

where $i$ represents the individual and $S W B_{i}^{k}$ represents the SWB indicator of type $k$, with $k$ being any of the following four types: the Cantril Ladder (cognitive SWB); life satisfaction (cognitive SWB); affect balance (affective SWB); and eudaimonia. $\gamma_{1}$ is a constant. The main independent variable, consumption $_{i}$, represents the monthly total consumption of individual $i . X_{i j}$ are control variables that have been used in prior studies of SWB (i.e., age, gender, level of subjective health, education, marriage, having children, having grandchildren, and personality). ${ }^{9}{ }^{10}$ Furthermore, since consumption expenditure is reported per household, we also control for the number of people in the household. ${ }^{11}$ Finally, $\alpha_{j}$ are coefficients and $\epsilon_{1}$ is the uncorrelated error term.

Because we are concerned about the different effects of material and relational consumption, our empirical model is extended as follows:

$$
S W B_{i}^{k}=\gamma_{2}+g_{1}\left(C_{1 i}\right)+g_{2}\left(C_{2 i}\right)+\sum_{j} \beta_{j} Y_{i j}+\epsilon_{2}
$$

where material consumption $\left(C_{1}\right)$ and relational consumption $\left(C_{2}\right)$ are included on the righthand side. Like in Eq. (1), $\gamma_{1}$ is a constant, $\epsilon_{2}$ is an uncorrelated error term, and $Y_{i j}$ stands for other control variables with $\beta_{j}$ as the coefficient. To ensure that residual consumption does not affect our results, we also control for other consumption ( consumption $_{i}-\left(C_{1 i}+C_{2 i}\right)$ ).

Using a reduced form of our theoretical construct, this study aims to clearly explore the different functional forms of consumption. Thus, we utilize nonparametric functions for consumption. Regarding the other explanatory variables, we account for parametric functions and apply semiparametric regression, as in prior studies. Previous studies of SWB

\footnotetext{
9 Individuals who have lower income or fewer assets may at the same time have lower SWB and lower consumption levels. Those with less income/fewer assets may also have less leisure time and therefore, spend less time with friends and family, which may at the same time reduce relational consumption and SWB due to lack of social interaction. Similarly, those who are in a better emotional state or evaluate life more positively may do so because they have more friends, and because they have more friends and enjoy the relationships with them, they may also spend more on relational consumption. To consider these omitted variable problems, we include additional control variables, such as annual household income, assets, level of trust in family, neighborhoods, friends, and frequency of participation in local community activities in our estimation models. These results are almost the same as our main results shown in the next section. These results for the robustness check are available as electronic supplemental material.

${ }^{10}$ In the panel data, it is possible to consider the fixed effects from individuals in order to discount personality and temperament. However, because this study utilizes cross-sectional data, it is not possible to consider the fixed effects of individual attributes. When questions regarding life satisfaction are answered, the statistical dispersion from the choice of either positive or negative responses may cause a response bias. To account for this dispersion, the indicators reflecting personality are subsumed in the explanatory variables.

11 Schröder et al. (2015) focus on household size and economy of scale with regard to energy consumption.
} 
using nonparametric methods include Blanchflower and Oswald (2008), Ferreira and Moro (2010), and Stevenson and Wolfers (2013).

There are two obstacles to the usual nonparametric multiple regressions. First, as the number of explanatory variables increases, the sparseness of the data inflates the variance in the estimates, and massive amounts of data are required for accurate estimation. Second, because a nonparametric regression does not provide an equation relating the average response to the independent variables, we need to display the response surface graphically by slicing the surface. When the number of explanatory variables exceeds three, the shape of the sliced surface becomes difficult to interpret (see Hastie and Tibshirani 1990).

These problems have spurred the development of additive regression models (Stone 1985). In this study, we use generalized additive models. We use cubic spline smoothing ${ }^{12}$ iteratively to minimize the partial residuals that remain after removing the influence of the other variables in the model. In this model, a Bayesian approach is employed to derive standard errors and confidence intervals. Our estimation technique follows Wood (2004, 2008).

\subsection{Data}

This study relies on data from 9,635 subjects who submitted valid responses from a total of 13,690 respondents to our original Internet survey conducted in March 2017 across Japan. ${ }^{13}$ The main dependent variables for SWB are summarized in Table 1, while Table 2 shows the control variables.

The survey selected respondents based on prefectural demographics, such as population, gender, and age ratios, to ensure that the sample represented Japan's population. The survey was conducted as follows. First, an invitation was emailed from the internet survey company to relevant cohorts from their 1 million-plus registered monitors in Japan. To obtain a random sample, e-mails were sent to selected monitors based on prefectural demographics, such as population, gender, and age, and basic attributes, such as income level, and education. About $67 \%$ of the individuals who were contacted completed the survey.

Consumption is of utmost interest among the independent variables. In particular, we ask the questions listed in Table 3 to differentiate material consumption from relational consumption. Material consumption represents the consumption of goods, both consumer durables and others, but not services. Our measure of relational consumption pertains to consumption involving interactions with family, relatives, friends, and acquaintances. While monthly household consumption expenditure includes expenditures for housing, cars, and bikes, both material consumption and relational consumption do not. In addition, monthly household consumption expenditure includes medical expenses, insurance, and educational expenses, which are not included in either material or relational consumption.

In Table 4, we show the descriptive statistics of both the dependent and explanatory variables, while the frequencies of each type of consumption expenditure are shown in Fig. 1. Among SWB indexes, we find that affect balance and the Cantril ladder have the smallest standard deviations and that subjective happiness has the highest mean.

\footnotetext{
12 When we use the loess function in place of the cubic spline function, the results are almost the same.

13 There were a total of 13,690 respondents. After eliminating samples with the responses "I don't know/I don't want to answer this question" to questions regarding consumption and samples deemed incompatible based on criteria established to weed out invalid responses, 9,635 eligible subjects remained. The data that support the findings of this study are available from the corresponding author on reasonable request.
} 


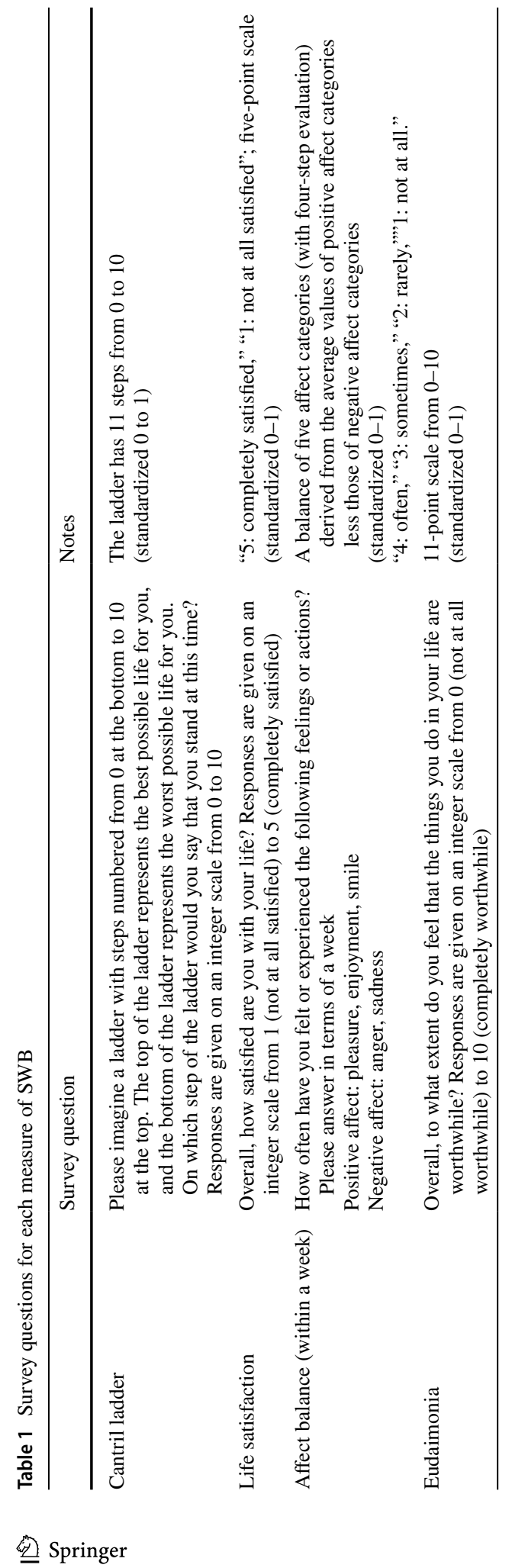




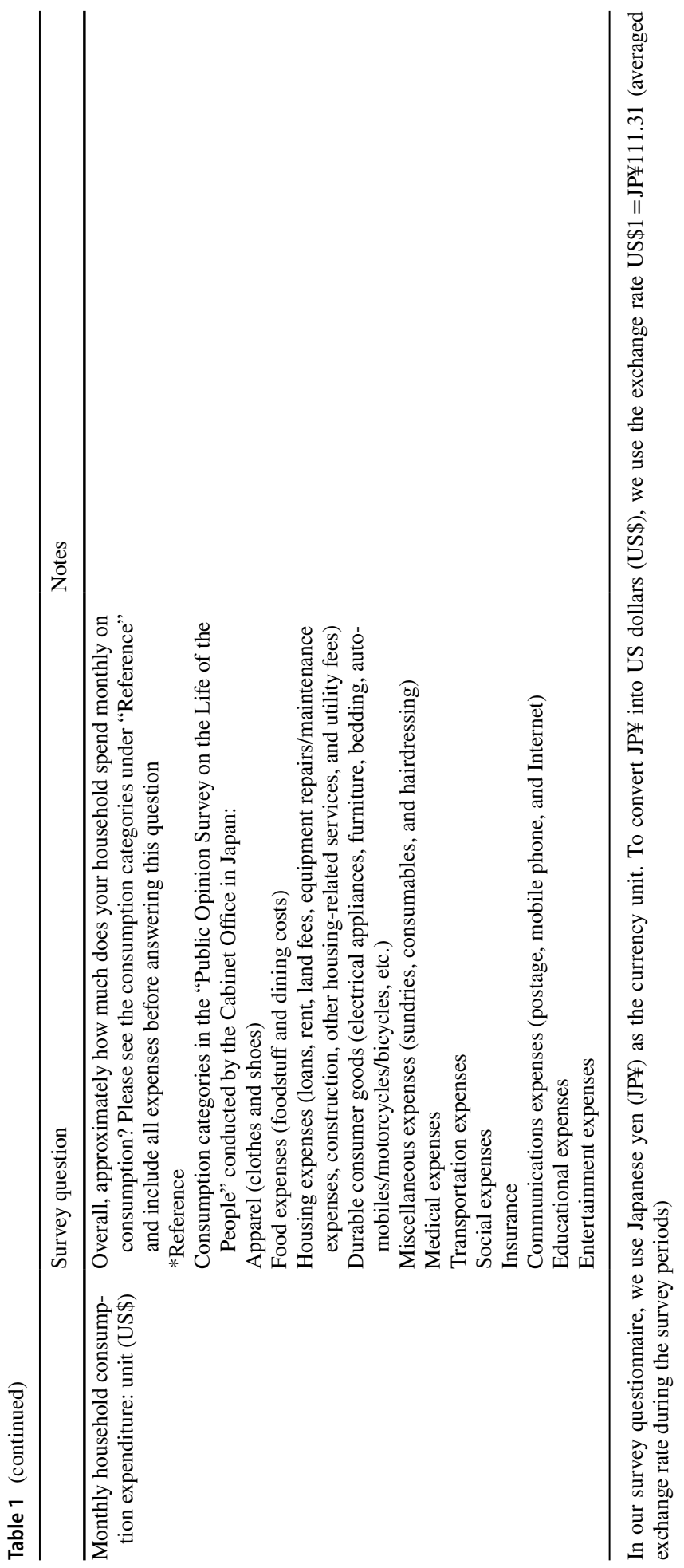




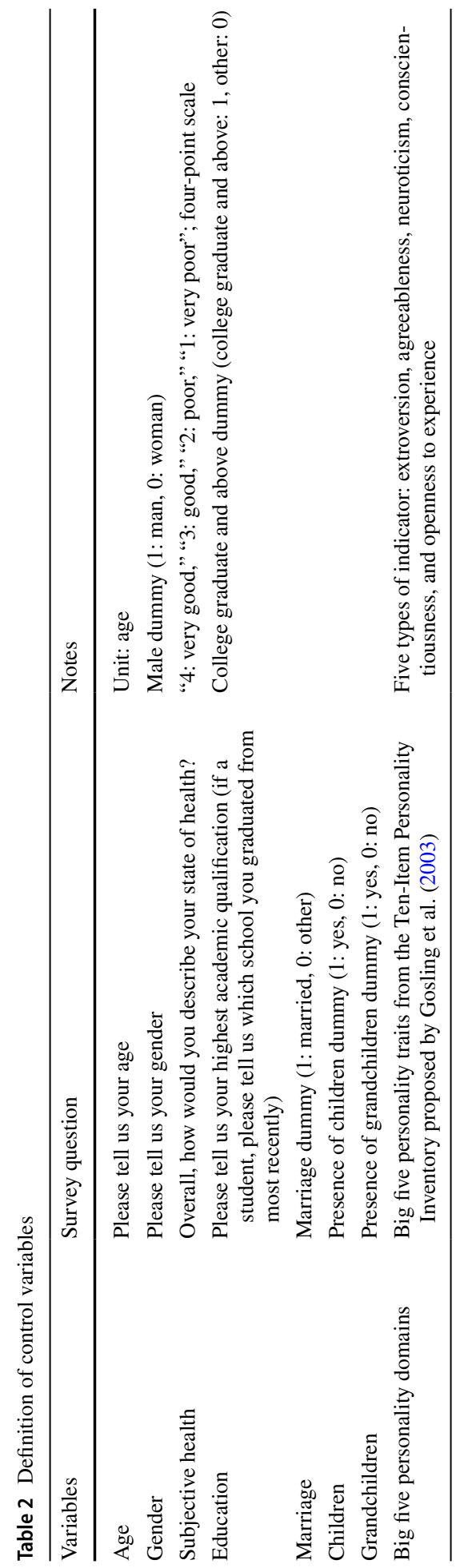


Table 3 Questions regarding types of consumption

\begin{tabular}{|c|c|}
\hline Material consumption (US\$) & $\begin{array}{l}\text { What is the average monthly amount spent in your household to purchase } \\
\text { "goods" (electrical appliances, furniture, clothes, shoes, publications, } \\
\text { and other sundries, excluding expenditure related to housing, cars, and } \\
\text { bikes)? }\end{array}$ \\
\hline Relational consumption (US\$) & $\begin{array}{l}\text { What is the average monthly amount spent in your household on "con- } \\
\text { sumption relating to interactions with your family, relatives, friends, } \\
\text { and acquaintances" (e.g., travel, gifts, dining with them in your own } \\
\text { home or outside, excluding expenditure related to housing, cars, and } \\
\text { bikes)? }\end{array}$ \\
\hline
\end{tabular}

Table 4 Basic statistical values of variables in the analysis

\begin{tabular}{|c|c|c|c|c|c|}
\hline Variable & $\begin{array}{l}\text { Number of } \\
\text { observations }\end{array}$ & Mean & $\begin{array}{l}\text { Standard } \\
\text { deviation }\end{array}$ & Minimum & Maximum \\
\hline Cantril ladder (standardized: $0-1$ ) & 9635 & 0.570 & 0.212 & 0 & 1 \\
\hline Life satisfaction (standardized: $0-1$ ) & 9635 & 0.571 & 0.263 & 0 & 1 \\
\hline Affect balance (standardized: $0-1$ ) & 9635 & 0.584 & 0.182 & 0 & 1 \\
\hline Eudaimonia (standardized: $0-1$ ) & 9635 & 0.594 & 0.254 & 0 & 1 \\
\hline Total monthly household expenditure (US\$) & 9635 & 1715 & 997 & 224 & 4938 \\
\hline Total monthly material consumption (US\$) & 9635 & 235 & 288 & 22 & 4492 \\
\hline Total monthly relational consumption (US\$) & 9635 & 188 & 223 & 0 & 3144 \\
\hline Male dummy & 9635 & 0.583 & 0.493 & 0 & 1 \\
\hline Age & 9635 & 49.5 & 11.2 & 18 & 75 \\
\hline Subjective health & 9635 & 2.79 & 0.778 & 1 & 4 \\
\hline Marriage dummy & 9635 & 0.698 & 0.459 & 0 & 1 \\
\hline Children dummy & 9635 & 0.603 & 0.489 & 0 & 1 \\
\hline Number of people in household & 9635 & 2.70 & 1.26 & 1 & 10 \\
\hline Grandchildren dummy & 9635 & 0.141 & 0.348 & 0 & 1 \\
\hline College graduate or above dummy & 9635 & 0.502 & 0.500 & 0 & 1 \\
\hline Extroversion & 9635 & 1.86 & 0.635 & 1 & 3 \\
\hline Agreeableness & 9635 & 2.39 & 0.508 & 1 & 3 \\
\hline Neuroticism & 9635 & 2.15 & 0.574 & 1 & 3 \\
\hline Conscientiousness & 9635 & 1.96 & 0.588 & 1 & 3 \\
\hline Openness to experience & 9635 & 2.00 & 0.547 & 1 & 3 \\
\hline
\end{tabular}

\section{Estimation Results}

The estimation results for the entire sample are summarized in Figs. 2, 3a, and b. In each figure, the horizontal axis corresponds to total monthly household consumption expenditure, material consumption, and relational consumption, respectively, while the SWB indicator is shown on the vertical axis. The solid line is the estimated consumption function curve, while the dotted lines represent the $95 \%$ confidence intervals. " 0 " on the vertical axis denotes the sample's average SWB. Table 5 shows the saturation points (if any) and model fit statistics. We find that the smooth term of Eq. (1) is statistically significant. 

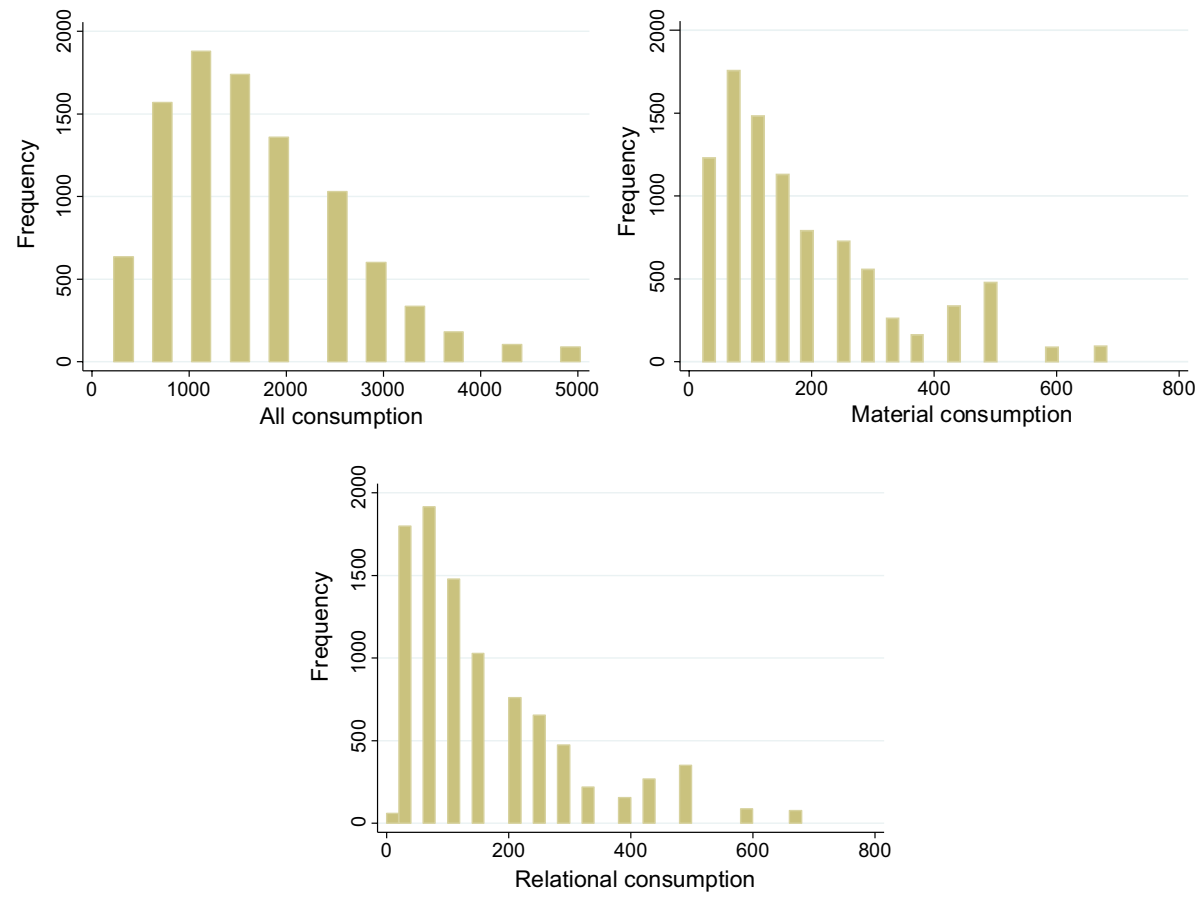

Fig. 1 Frequency of each type of consumption expenditure per month (US\$)

Figure 2 can be divided into two groups: the upper panels show the effects on the Cantril ladder, life satisfaction, and eudaimonia (Group 1), while the lower panels show the effects on affect balance (Group 2). We find that there might not be satiation for Group 1 in the upper panels of Fig. 2. The sluggish growth of SWB is even more evident for Group 2 and seems to reach satiation at approximately US\$2,000, as shown in the lower panels of Fig. 2. In addition, we find a smaller marginal effect of consumption on the Cantril ladder, eudaimonia, and affect balance than on life satisfaction from US\$0 to approximately US\$1,500.

The somewhat ambiguous results shown in Fig. 2 lead us to examine the relationship between the SWB indicators and the consumption categories in Eq. (2). Figures 3a and $b$ depict the estimation results for material consumption expenditure and relational consumption expenditure, respectively. Tables 6 and 7 show the saturation point (if any) and model fit statistics.

We find that the smooth terms of Eq. (2) is statistically significant, as shown in Fig. $3 \mathrm{a}$ and $\mathrm{b}$. In the figures, we find saturation points for material consumption in the case of both Group 1 and Group 2, while no such saturation state exists for relational consumption. Unlike total consumption, Fig. 3a and b show that subjective happiness has a similar trend to that of the Cantril ladder, life satisfaction, and eudaimonia, with a smaller marginal effect of consumption on affect balance than on the other SWB indexes. Furthermore, the marginal effect of material consumption tends to be lower than that of relational consumption for all SWB indices. 

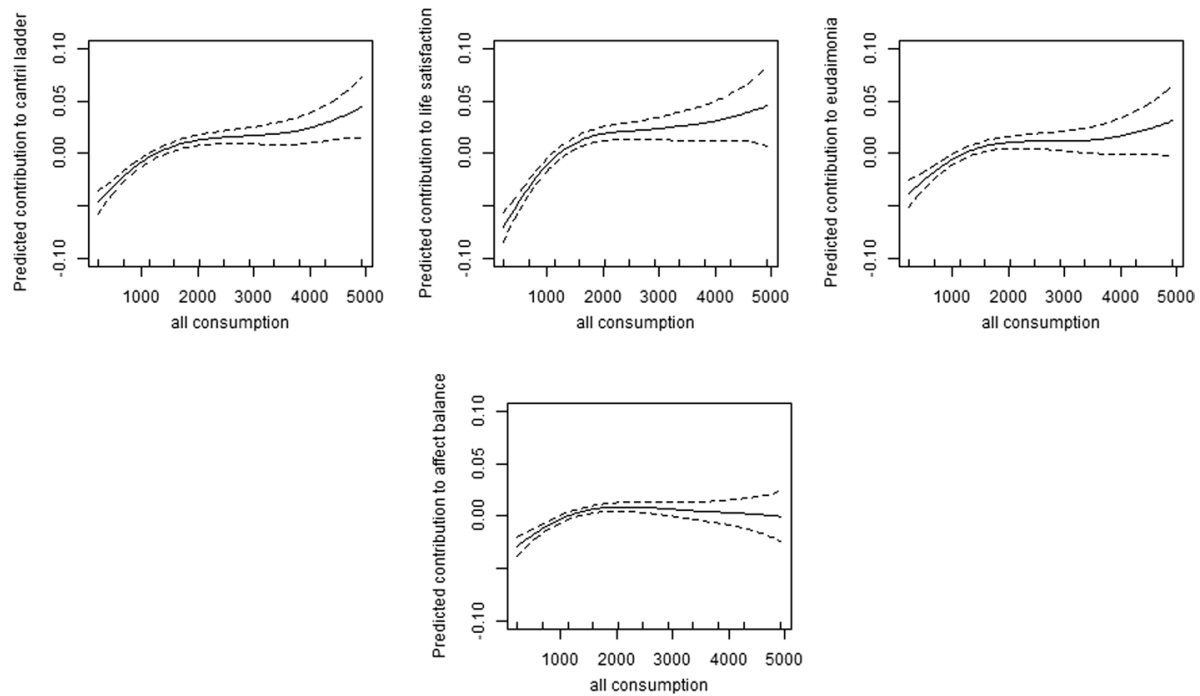

Fig. 2 Relationship between Consumption and SWB Indicators by Type. Notes The vertical axis represents the effects on each type of SWB indicator, while the horizontal axis represents the monthly household consumption expenditure (US\$). The solid lines constitute the nonparametric function curves, while the dotted lines denote the $95 \%$ confidence intervals

\section{Discussion and Conclusion}

A saturation point can be hypothesized such that SWB does not grow even if consumption or income grows, as the well-known Easterlin (1974) paradox suggests. Previous studies have mainly addressed the effect of income, but the breakdown of income into different consumption types should be more relevant for SWB, partly because a nontrivial portion of income is saved.

Our empirical results are discussed as follows. First, the consumption satiation effect in terms of SWB is not strongly evident. Compared with previous studies, we note similarities to Kahneman and Deaton (2010) in that total consumption contributes to the Cantril ladder but no more than a certain threshold with regard to Kahneman and Deaton's (2010) definition of emotional indicators (i.e., affective measures) of SWB. Changing the explanatory variable from income to total consumption does not change Kahneman and Deaton's (2010) conclusion. This observation can be explained in several ways. One is a situation in which an individual allocates income to consumption and savings in an optimal fashion so that the effects of income and consumption on SWB are equalized on the margin. Another explanation is more applicable to countries where the household savings rate is near zero, such as the case of Portugal and Greece over the past several years (OECD 2018), so that the effects of income and total consumption are trivially on par with each other. In light of Seligman's (2002) theory of authentic happiness and Haybron (2000), our results suggest that total consumption contributes to life satisfaction (prudential happiness) and eudaimonia (perfectionist happiness) but no more than a certain threshold for hedonic well-being (psychological happiness).

Furthermore, our theoretical formulation uniquely attempts to differentiate the SWB indices by explaining instantaneous versus intertemporal utility maximization by individuals. This argument is consistent with Kozma et al. (1992), who theorize that happiness is 

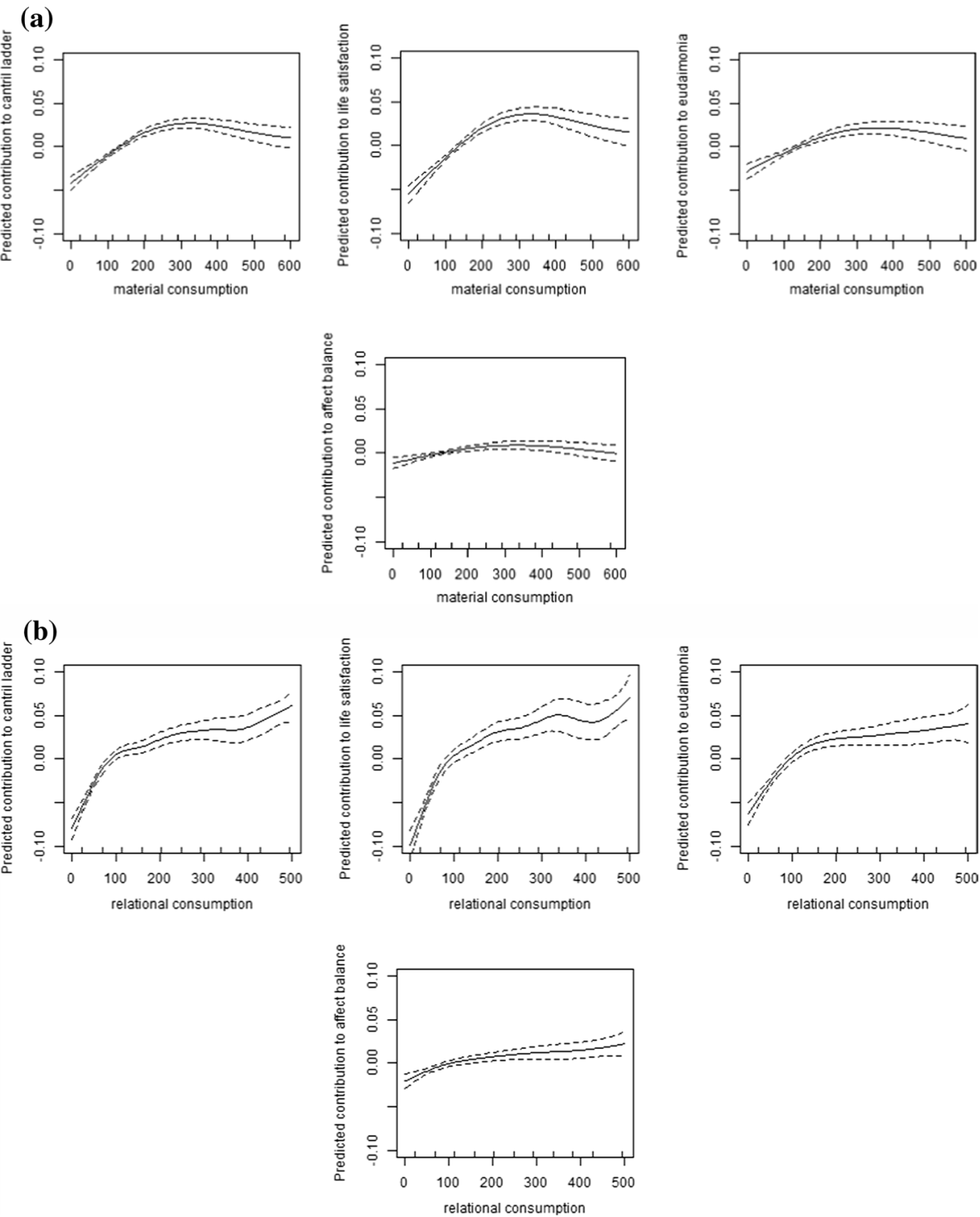

Fig. 3 a Relationship between monthly material consumption expenditure and SWB. b Relationship between monthly relational consumption expenditure and SWB. Note Because of the wide confidence intervals, the results for consumption expenditure in the top $5 \%$ range are omitted

a direct function of two psychological states, one short term and the other long term. The underlying assumption is that short-term, instantaneous utility yields an affective measure of SWB, while long-term intertemporal utility leads to a cognitive measure of SWB.

Our empirical results suggest that total consumption contributes to cognitive measures of SWB (Cantril ladder, life satisfaction) and eudaimonia, while there is a certain threshold for affective measures (affect balance). This finding is consistent with the literature on the income-SWB relationship. 
Table 5 Satiation point and model fit statistics (Total consumption)

\begin{tabular}{lllr}
\hline & $\begin{array}{l}\text { Satiation point for monthly consump- } \\
\text { tion expenditure (US\$) }\end{array}$ & $\begin{array}{l}\text { Approximate significance of } \\
\text { smooth term: F statistics }\end{array}$ & $\mathrm{R}^{2}$ \\
\hline Cantril ladder & - & $21.59^{* * *}$ & 0.360 \\
Life satisfaction & - & $25.9 * * *$ & 0.282 \\
Eudaimonia & - & $10.15^{* * *}$ & 0.305 \\
Affect balance & 2184 & $10.66^{* * *}$ & 0.354 \\
\hline
\end{tabular}

$*, * *$, and $* * *$ indicate significance at the $10 \%, 5 \%$, and $1 \%$ levels, respectively

Table 6 Satiation point and model fit statistics (Material consumption)

\begin{tabular}{lllr}
\hline & $\begin{array}{l}\text { Satiation point for monthly consump- } \\
\text { tion expenditure (US\$) }\end{array}$ & $\begin{array}{l}\text { Approximate significance of } \\
\text { smooth term: F statistics }\end{array}$ & $\mathrm{R}^{2}$ \\
\hline Cantril ladder & 295 & $7.446^{* * * *}$ & 0.375 \\
Life satisfaction & 314 & $8.153^{* * *}$ & 0.296 \\
Eudaimonia & 330 & $2.768^{* * *}$ & 0.311 \\
Affect balance & 283 & $2.038^{*}$ & 0.355 \\
\hline
\end{tabular}

$*$, **, and $* * *$ indicate significance at the $10 \%, 5 \%$, and $1 \%$ levels, respectively

Table 7 Satiation point and model fit statistics (Relational consumption)

\begin{tabular}{lllr}
\hline & $\begin{array}{l}\text { Satiation point for monthly consump- } \\
\text { tion expenditure (US\$) }\end{array}$ & $\begin{array}{l}\text { Approximate significance of } \\
\text { smooth term: F statistics }\end{array}$ & $\mathrm{R}^{2}$ \\
\hline Cantril ladder & - & $23.040 * * *$ & 0.379 \\
Life satisfaction & - & $16.903 * * *$ & 0.301 \\
Eudaimonia & - & $19.169 * * *$ & 0.314 \\
Affect balance & - & $6.967 * * *$ & 0.352 \\
\hline
\end{tabular}

$*$, **, and $* * *$ indicate significance at the $10 \%, 5 \%$, and $1 \%$ levels, respectively

However, once material versus relational consumption is extracted from the total consumption data, we find that there are saturation points for all SWB indexes for material consumption. In other words, the classic Easterlin paradox applies to the consumption of material goods and services. The literature suggests that materialistic people tend to experience financial problems, such as getting into debt, engaging in compulsive shopping, and declaring bankruptcy (Roverts 2011), and show that materialism is negatively related to life satisfaction. Our results are consistent with those of Kasser and Sheldon (2002), because the marginal effect of material consumption tends to be lower than that of relational consumption for all SWB indexes.

Finally, our results show that SWB grows without clear limits for relational consumption for all SWB indexes. This implies that relational consumption is expected to be key in improving both short-term and long-term well-being, as defined in our theoretical 
formulation. In other words, setting aside expenditures for relational consumption always enables an individual to achieve "sustainable" well-being. ${ }^{14}$

Among the literature on the consumption expenditure-SWB relationship, Perez-Truglia (2013) and Wu (2019) demonstrate that conspicuous spending increases life satisfaction. For example, Wu (2019) suggests that it is an individual's conspicuous consumption expenditure relative to that of reference group households that really matters. In this regard, the current study's limitation is that we cannot fully consider the detailed breakdown of relational consumption, which includes both conspicuous and inconspicuous consumption. In other words, if people include some of their conspicuous consumption in relational consumption, our estimation results partly reflect an individual's conspicuous consumption expenditure relative to that of other households in his or her reference group. Moreover, if some relational consumption goods are conspicuous while others are not, they have different impacts on short- and long-term well-being (Arrow and Dasgupta, 2009). Therefore, further studies that fully distinguish conspicuous consumption and relational consumption are needed.

Another challenge is to compare the effects of consumption versus income explicitly. Conventional price theory suggests that under utility maximization, indirect utility can be written solely as a function of relative prices (of general goods and relational goods in our context) and income as consumption variables are substituted away. To compare the marginal effects of consumption and income on SWB, therefore, we need to scale direct and indirect utility functions, which poses an empirical challenge.

Finally, many studies have been conducted using SWB indicators to elucidate the importance of social capital and leisure (e.g., Rodríguez-Pose and von Berlepsch 2014; Wang and Wong 2014; Rotondi et al. 2017). It is assumed that relational consumption is deeply connected with a plenitude of social capital and leisure. As we show in the dynamic model in Appendix, digging more deeply into the interaction between relational consumption and social capital is an important direction for future research.

Acknowledgement We would like to thank the editors and two anonymous reviewers for their insightful comments.

Funding This research was supported by the Environment Research and Technology Development Fund (S-16) of the Ministry of the Environment, Japan.

Open Access This article is licensed under a Creative Commons Attribution 4.0 International License, which permits use, sharing, adaptation, distribution and reproduction in any medium or format, as long as you give appropriate credit to the original author(s) and the source, provide a link to the Creative Commons licence, and indicate if changes were made. The images or other third party material in this article are included in the article's Creative Commons licence, unless indicated otherwise in a credit line to the material. If material is not included in the article's Creative Commons licence and your intended use is not permitted by statutory regulation or exceeds the permitted use, you will need to obtain permission directly from the copyright holder. To view a copy of this licence, visit http://creativecommons.org/licenses/by/4.0/.

14 "Subjective happiness" can be defined as a cognitive measure of SWB (e.g., OECD 2013). However, the literature suggests that subjective happiness is easily influenced by feelings (Deiner et al. 2010). Thus, subjective happiness can be neither a purely cognitive nor affective SWB measure. Our estimation results, including those using subjective happiness shown in the electronic material, empirically suggest that the subjective happiness measure has both cognitive and affective components. 


\section{Appendix}

Here, we show a model in which relational consumption leads to social capital creation in a standard dynamic optimality framework. The representative agent is assumed to be

$$
\max V(t)=\int_{t}^{\infty} U\left(C_{1}, C_{2}\right) e^{-\delta(\tau-t)} d \tau
$$

where $\delta>0$ is the pure rate of time preference. Capital changes according to the following equation of motion:

$$
\dot{K}=Y-C_{1}-C_{2}=F(K, S)-C_{1}-C_{2}
$$

where $Y=F(K, S)$ stands for output. Both capital $K$ and social capital $S$ are used in the production process, and their marginal products are positive: that is, $F_{K}>0$ and $F_{S}>0$. The latter social capital dynamic is simply postulated to be a function of relational consumption $C_{2}$ :

$$
\dot{S}=f\left(C_{2}\right),
$$

where $f$ embodies the possible depreciation of social capital, but we assume $f^{\prime}>0$ for simplicity. Avoiding unnecessary technical details, we ensure only that the necessary conditions for optimality include the following:

$$
\begin{gathered}
U_{1}=\lambda \\
U_{2}=\lambda-\mu f^{\prime} \\
-\lambda F_{K}=\dot{\lambda}-\delta \lambda \\
-\lambda F_{S}=\dot{\mu}-\delta \mu
\end{gathered}
$$

where $\lambda$ and $\mu$ are co-state variables associated with capital and social capital, respectively.

According to Eq. (3), the marginal utility of material consumption is equated with the shadow price of capital. The marginal utility of relational consumption is revealed in a different form in Eq. (4). ${ }^{15}$ Relational consumption is determined in such a manner as to include its persistent effect on social capital formation, which then affects productivity. This demonstrates that different coefficients should be attached in regressing utility on material and relational consumption.

Moreover, for a particular type of consumption, marginal utility $(\partial U / \partial C)$ and marginal intertemporal utility $(\partial V / \partial C)$ differ in general. Since the current-value Hamiltonian for the above problem is the return on intertemporal utility (Weitzman 1976), marginal intertemporal utility is the present value of the difference between marginal (instantaneous) utility and the shadow price of capital. Thus, in the optimal economy, marginal intertemporal

\footnotetext{
${ }^{15}$ Equations (5) and (6) show the paths of shadow prices of capital and social capital. Combined with efficiency conditions (3) and (4), it is possible to derive the time paths of material and relational consumption; however, this is not our purpose in this study.
} 
utility should be zero; in a nonoptimizing economy, it could be nonzero. In both economies, we ensure that it unambiguously differs from marginal (instantaneous) utility.

\section{References}

Ahuvia, A., \& Friedman, D. (1998). Income, consumption, and subjective well-being: Toward a composite macromarketing model. Journal of Macromarketing, 18(2), 153-168.

Alpizar, F., Carlsson, F., \& Johansson-Stenman, O. (2005). How much do we care about absolute versus relative income and consumption? Journal of Economic Behavior and Organization, 56(3), 405-421.

Andrews, F. M., \& McKennell, A. C. (1980). Measures of self-reported well-being: Their affective, cognitive, and other components. Social Indicators Research, 8, 127-155.

Andrews, F. M., \& Withey, S. B. (1976). Social indicators of well-being: America's perception of life quality. New York: Plenum Press.

Arrow, K. J., \& Dasgupta, P. S. (2009). Conspicuous consumption, inconspicuous leisure. The Economic Journal, 119(541), F497-F516.

Bayer, C., \& Juessen, F. (2015). Happiness and the persistence of income shocks. American Economic Journal Macroeconomics, 7(4), 160-187.

Becchetti, L., Pelloni, A., \& Rossetti, F. (2008). Relational goods, sociability, and happiness. Kyklos, 61(3), 343-363.

Benjamin, D. J., Heffetz, O., Kimball, M. S., \& Rees-Jones, A. (2012). What do you think would make you happier? What do you think you would choose? American Economic Review, 102(5), 2083-2110.

Benjamin, D. J., Heffetz, O., Kimball, M. S., \& Szembrot, N. (2014). Beyond happiness and satisfaction: Toward well-being indices based on stated preference. American Economic Review, 104(9), 2698-2735.

Bhattacharjee, A., \& Mogilner, C. (2014). Happiness from ordinary and extraordinary experiences. Journal of Consumer Research, 41(1), 1-17.

Binder, M., \& Blankenberg, A. K. (2017). Green lifestyles and subjective well-being: More about selfimage than actual behavior? Journal of Economic Behavior and Organization, 137, 304-323.

Binder, M., \& Freytag, A. (2013). Volunteering, subjective well-being and public policy. Journal of Economic Psychology, 34, 97-119.

Bjørnskov, C. (2003). The happy few: Cross-country evidence on social capital and life satisfaction. Kyklos, 56(1), 3-16.

Bjørnskov, C. (2006). The multiple facets of social capital. European Journal of Political Economy, 22(1), 22-40.

Blanchflower, D. G., \& Oswald, A. J. (2007). Hypertension and happiness across nations. Mimeo: University of Warwick.

Blanchflower, D. G., \& Oswald, A. J. (2008). Is well-being U-shaped over the life cycle? Social Science Medicine, 66(8), 1733-1749.

Böckerman, P., \& Ilmakunnas, P. (2006). Elusive effects of unemployment on happiness. Social Indicators Research, 79(1), 159-169.

Bonsang, E., \& Klein, T. J. (2012). Retirement and subjective well-being. Journal of Economic Behavior Organization, 83(3), 311-329.

Brief, A. P., \& Roberson, L. (1989). Job attitude organization: An exploratory study. Journal of Applied Social Psychology, 19, 717-727.

Bruni, L., \& Stanca, L. (2008). Watching alone: Relational goods, television and happiness. Journal of Economic Behavior Organization, 65(3-4), 506-528.

Cai, S., \& Park, A. (2016). Permanent income and subjective well-being. Journal of Economic Behavior and Organization, 130, 298-319.

Campbell, A. C. (1976). Subjective measures of well-being. American Psychologist, 31, 117-124.

Cantril, H. (1965). The pattern of human concerns. New Brunswick, NJ: Rutgers University Press.

Caprariello, P. A., \& Reis, H. T. (2013). To do or to have, or to share? valuing experiences over material possessions depends on the involvement of others. Journal of Personal Social Psychology, 104, 199-215.

Clark, A. E., Frijters, P., \& Shields, M. A. (2008). Relative income, happiness, and utility: An explanation for the Easterlin paradox and other puzzles. Journal of Economic Literature, 46(1), 95-144.

Crooker, K. J., \& Near, J. P. (1995). Happiness and satisfaction: Measures of affect and cognition? In H. L. Meadow \& M. J. Sirgy (Eds.), Development in quality-of-life studies in marketing (Vol. 5, pp. 
160-166). DeKalb, IL: Academy of Marketing Science and the International Society for Qualityof-Life Studies.

Dasgupta, P. (2014). Sustainability and the determinants of personal consumption. In D. Southerton \& A. Ulph (Eds.), Sustainable consumption: Multi-disciplinary perspectives in honour of Sir Partha Dasgupta, 2104 (pp. 43-87). Oxford: Oxford University Press.

Deaton, A. (2008). Income, health, and well-being around the world: Evidence from the gallup world poll. Journal of Economic Perspectives, 22(2), 53-72.

DeLeire, T., \& Kalil, A. (2010). Does consumption buy happiness? Evidence from the United States. International Review of Economics, 57(2), 163-176.

Di Tella, R., Haisken-De New, J., \& MacCulloch, R. (2010). Happiness adaptation to income and to status in an individual panel. Journal of Economic Behavior and Organization, 76(3), 834-852.

Di Tella, R., MacCulloch, R. J., \& Oswald, A. J. (2001). Preferences over inflation and unemployment: Evidence from surveys of happiness. American Economic Review, 91(1), 335-341.

Di Tella, R., MacCulloch, R. J., \& Oswald, A. J. (2003). The macroeconomics of happiness. Review of Economics and Statistics, 85(4), 809-827.

Diener, E. (1984). Subjective well-being. Psychological Bulletin, 75, 542-575.

Diener, E., Emmons, R. A., Larsen, R. J., \& Griffin, S. (1985). The satisfaction with life scale. Journal of Personality Assessment, 49(1), 71-75.

Diener, E., Kahneman, D., Tov, W., \& Arora, R. (2010). Income's association with judgements of life versus feelings. In E. Diener, J. Helliwel, \& D. Kahneman (Eds.), International differences in well-being (pp. 3-15). Oxford: Oxford University Press.

Dolan, P., Peasgood, T., \& White, M. (2008). De we really know what makes us happy? A review of the economic literature on the factors associated with subjective well-being. Journal of Economic Psychology, 29(1), 94-122.

Donati, P. (2010). Relational sociology: A new paradigm for the social sciences. London: Routledge.

Dumludag, D. (2015). Consumption and life satisfaction at different levels of economic development. International Review of Economics, 62(2), 163-182.

Dunn, E. W., \& Weidman, A. C. (2015). Building a science of spending: Lessons from the past and directions for the future. Journal of Consumer Psychology, 25(1), 172-178.

Easterlin, R. A. (1974). Does economic growth improve the human lot? Some empirical evidence. In P. David \& M. Reder (Eds.), Nations and households in economic growth (pp. 89-125). Cambridge: Academic Press.

Easterlin, R. A. (1995). Will raising the incomes of all increase the happiness of all? Journal of Economic Behavior and Organization, 27(1), 35-47.

Easterlin, R. A. (2001). Income and happiness: Towards a unified theory. The Economic Journal, 111(473), 465-484.

Ferreira, S., \& Moro, M. (2010). On the use of subjective well-being data for environmental valuation. Environmental and Resource Economics, 46(3), 249-273.

Ferrer-i-Carbonell, A. (2005). Income and well-being: An empirical analysis of the comparison income effect. Journal of Public Economics, 89, 997-1019.

Frank, R. (1999). Luxury fever: Money and happiness in an era of excess. New York: Free Press.

Frey, B. S., \& Stutzer, A. (2002). Happiness and economics: How the economy and institutions affect well-being. Princeton, NJ: Princeton University Press.

Frey, B. S. Stutzer, A. (2003). Testing theories of happiness. Working paper, Institute for Empirical Research in Economics, University of Zurich.

Gardner, J., \& Oswald, A. J. (2007). Money and mental wellbeing: A longitudinal study of mediumsized lottery wins. Journal of Health Economics, 26, 49-60.

Gilovich, T., Kumar, A., \& Jampol, L. (2015). A wonderful life: Experiential consumption and the pursuit of happiness. Journal of Consumer Psychology, 25(1), 138-151.

Gimenez-Nadal, J. I., \& Molina, J. A. (2015). Voluntary activities and daily happiness in the United States. Economic Inquiry, 53(4), 1735-1750.

Glaeser, E. L., Gottlieb, J. D., \& Ziv, O. (2016). Unhappy cities. Journal of Labor Economics, 34(S2), $129-182$.

Gokdemir, O. (2015). Consumption, savings and life satisfaction: The Turkish case. International Review of Economics, 62(2), 183-196.

Gosling, S. D., Rentfrow, P. J., \& Swann, W. B. (2003). A very brief measure of the Big-Five personality domains. Journal of Research in Personality, 37(6), 504-528.

Graham, C., \& Pettinato, S. (2002). Happiness and hardship: Opportunity and insecurity in new market economies. Washington, DC: The Brookings Institution Press. 
Guillen-Royo, M. (2008). Consumption and subjective wellbeing: Exploring basic needs, social comparison, social integration and hedonism in Peru. Social Indicators Research, 89(3), 535-555.

Hastie, T. J., \& Tibshirani, R. J. (1990). Generalized additive models. New York: Chapman and Hall.

Haybron, D. M. (2000). Two philosophical problems in the study of happiness. Journal of Happiness Studies, $1,207-225$.

Headey, B., Muffels, R., \& Wooden, M. (2008). Money does not buy happiness: or does it? A reassessment based on the combined effects of wealth, income and consumption. Social Indicators Research, 87(1), 65-82.

Helliwell, J. F. (2003). How's life? Combining individual and national variables to explain subjective wellbeing. Economic Modelling, 20, 331-360.

Helliwell, J. F., Layard, R., \& Sachs, J. (2012). World happiness report. New York: Earth Institute.

Jebb, A. T., Tay, L., Diener, E., \& Oishi, S. (2018). Happiness, income satiation and turning points around the world. Nature Human Behavior, 2(1), 33-38.

Kahneman, D. (1999). Objective happiness. In D. Kahneman, E. Diener, \& N. Schwarz (Eds.), Well-being The foundations of hedonic psychology. Newyork: Russell Sage Foundation.

Kahneman, D. (2011). Thinking, fast and slow. New York: Farrar Straus and Giroux.

Kahneman, D., \& Deaton, A. (2010). High income improves evaluation of life but not emotional well-being. Proceedings of the National Academy of Sciences, 107(38), 16489-16493.

Kahneman, D., \& Krueger, A. B. (2006). Developments in the measurement of subjective well-being. Journal of Economic Perspectives, 20(1), 3-24.

Kasser, T., \& Sheldon, K. M. (2002). What makes for a merry Christmas? Journal of Happiness Studies, 3 , 313-329.

Kesebi, P., \& Diener, E. (2009). In pursuit of happiness: Empirical answers to philosophical questions. In E. Diener (Ed.), The science of well-being The collected works of Ed Diener. Dordrechit: Springer.

Kingdon, G. G., \& Knight, J. (2007). Community, comparisons and subjective well-being in a divided society. Journal of Economic Behavior and Organization, 64(1), 69-90.

Kozma, A., Fazio, R. D., Stones, M. J., \& Hannah, T. E. (1992). Long- and short-term affective states in happiness: Age and sex comparisons. Social Indicators Research, 27, 293-309.

Kumar, A., \& Gilovich, T. (2016). To do or to have, now or later? The preferred consumption profiles of material and experiential purchases. Journal of Consumer Psychology, 26(2), 169-178.

Layard, R. (2005). Happiness: Lessons from a new science. US: Penguin Books/Penguin Group.

Le Moglie, M., Mencarini, L., \& Rapallini, C. (2015). Is it just a matter of personality? On the role of subjective well-being in childbearing behavior. Journal of Economic Behavior and Organization, 117, 453-475.

Leigh, A., \& Wolfers, J. (2006). Happiness and the human development index: Australia is not a paradox. Australian Economic Review, 59, 176-184.

McKennell, A. C. (1978). Cognition and affect in perceptions of well-being. Social Indicators Research, 5, 389-426.

McKennell, A. C., \& Andrews, F. M. (1980). Models of cognition and affect in perceptions of well-being. Social Indicators Research, 8, 257-298.

Meier, S., \& Stutzer, A. (2008). Is volunteering rewarding in itself? Economica, 75(297), 39-59.

Michalos, A. C. (1980). Satisfaction and happiness. Social Indicators Research, 8, 385-422.

Nicolao, L., Irwin, J. R., \& Goodman, J. K. (2009). Happiness for sale: Do experiential purchases make consumers happier than material purchases? Journal of Consumer Psychology, 36, 188-198.

Nikolova, M., \& Nikolaev, B. N. (2018). Family matters: The effects of parental unemployment in early childhood and adolescence on subjective well-being later in life. Journal of Economic Behavior and Organization. (in press).

Noll, H. H., \& Weick, S. (2015). Consumption expenditures and subjective well-being: Empirical evidence from Germany. International Review of Economics, 62(2), 101-119.

OECD. (2013). OECD guidelines on measuring subjective well-being. OECD Publishing. https://doi. org/10.1787/9789264191655-en

OECD. (2018). Household savings (indicator). Doi: https://doi.org/10.1787/cfc6f499-en.

Office for National Statistics. (2011). Initial investigations into subjective well-being from the opinions survey. United Kingdom: Office for National Statistics.

Organ, D. W., \& Near, J. P. (1985). Cognition vs affect in measures of job satisfaction. International Journal of Psychology, 20, 241-253.

Oswald, A. J., \& Powdthavee, N. (2007). Obesity, unhappiness, and the challenge of affluence: theory and evidence. The Economic Journal, 117, 441-454.

Oswald, A. J., \& Powdthavee, N. (2008). Death, happiness, and the calculation of compensatory damages. The Journal of Legal Studies, 37(S2), S217-S252. 
Pandelaere, M. (2016). Materialism and well-being: The role of consumption. Current Opinion in Psychology, 10, 33-38.

Parducci, A. (1995). Happiness, pleasure, and judgment: The contextual theory and its applications. Mahwah NJ: Lawrence Erlbaum Associates.

Perez-Truglia, R. (2013). A test of the conspicuous-consumption model using subjective well-being data. The Journal of Socio-Economics, 45, 146-154.

Peterson, C., Park, N., \& Seligman, M. E. P. (2005). Orientations to happiness and life satisfaction: The full life versus the empty life. Journal of Happiness Studies, 6, 24-41.

Phillips, D. (2006). Quality of life: Concept, policy and practice. London: Routledge.

Powdthavee, N., Burkhauser, R., \& De Neve, J. (2017). Top incomes and human well-being: Evidence from the Gallup World Poll. Journal of Economic Psychology, 62, 246-257.

Rodríguez-Pose, A., \& von Berlepsch, V. J. (2014). Social capital and individual happiness in Europe. Journal of Happiness Studies, 15(2), 357-386.

Rotondi, V., Stanca, L., \& Tomasuolo, M. (2017). Connecting alone: Smartphone use, quality of social interactions and well-being. Journal of Economic Psychology, 63, 17-26.

Roverts, J. A. (2011). Shiny objects: Why we spend money we don't have in search of happiness we can't buy. New York: HarperCollins Publishers.

Sanjuan, P. (2011). Affect balance as mediating variable between effective psychological functioning and satisfaction with life. Journal of Happiness Studies, 12, 373-384.

Schröder, C., Rehdanz, K., Narita, D., \& Okubo, T. (2015). The decline in average family size and its implications for the average benefits of within-household sharing. Oxford Economic Papers, 67(3), $760-780$.

Seligman, M. E. P. (2002). Authentic happiness: Using the new positive psychology to realize your potential for lasting fulfilment. New York: The Free Press.

Sirgy, M. J. (2012). Social indicators research series: Vol. 50. The psychology of quality of life: Hedonic well-being, life satisfaction, and eudaimonia (2nd ed.). Springer Science + Business Media.

Stanca, L., \& Veenhoven, R. (2015). Consumption and happiness: An introduction. International Review of Economics, 62(2), 91-99.

Stevenson, B., \& Wolfers, J. (2008). Legal implications of the new research on happiness. Journal of Legal Studies, 37(S2), S33-S79.

Stevenson, B., \& Wolfers, J. (2013). Subjective well-being and income: Is there any evidence of satiation? American Economic Review, 103(3), 598-604.

Stiglitz, J. E., Sen, A., \& Fitoussi, J. P. (2010). Mismeasuring our lives: Why GDP doesn't add up. New York: The New Press.

Stone, C. J. (1985). Additive regression and other nonparametric models. The Annals of Statistics, 13(2), $689-705$.

Stutzer, A. (2004). The role of income aspirations in individual happiness. Journal of Economic Behavior and Organization, 54(1), 89-109.

Sumner, L. W. (1996). Welfare, happiness, and ethics. New York: Oxford University Press.

Sunstein, C. R., \& Ullmann-Margalit, E. (2001). Solidarity goods. Journal of Political Philosophy, 9(2), 129-149.

Tsurumi, T., \& Managi, S. (2017). Monetary valuations of life conditions in a consistent framework: The life satisfaction approach. Journal of Happiness Studies, 18(5), 1275-1303.

Van Boven, L., \& Gilovich, T. (2003). To do or to have? That is the question. Journal of Personality and Social Psychology, 85(6), 1193-1202.

Van Praag, B. M., Frijters, P., \& Ferrer-i-Carbonell, A. (2003). The anatomy of subjective well-being. Journal of Economic Behavior and Organization, 51(1), 29-49.

Veenhoven, R. (1984a). Conditions of happiness. Boston: Reidel.

Veenhoven, R. (1984b). Data book on happiness. Boston: Reidel.

Veenhoven, R. (1991). Is happiness relative? Social Indicators Research, 24, 1-39.

Veenhoven, R. (1994). World database of happiness: Correlates of happiness. Rotterdam, The Netherlands: Erasmus University.

Vendrik, M. C. (2013). Adaptation, anticipation and social interaction in happiness: An integrated errorcorrection approach. Journal of Public Economics, 105, 131-149.

Vitterso, J., Soholt, Y., Hetland, A., Alekseeva Thoresen, I., \& Roysamb, E. (2010). Was Hercules happy? Some answers from a functional model of human well-being. Social Indicators Research, 95, 1-18.

Wang, M., \& Wong, M. C. S. (2014). Happiness and leisure across countries: Evidence from international survey data. Journal of Happiness Studies, 15(1), 85-118.

Weitzman, M. L. (1976). On the welfare significance of national product in a dynamic economy. The Quarterly Journal of Economics, 90(1), 156-162. 
Welsch, H., \& Kühling, J. (2009). Determinants of pro-environmental consumption: The role of reference groups and routine behavior. Ecological Economics, 69(1), 166-176.

Winkelmann, L., \& Winkelmann, R. (1998). Why are the unemployed so unhappy? Evidence from panel data. Economica, 65, 1-15.

Wood, S. N. (2004). Stable and efficient multiple smoothing parameter estimation for generalized additive models. Journal of the American Statistical Association, 99, 673-686.

Wood, S. N. (2008). Fast stable direct fitting and smoothness selection for generalized additive models. Journal of the Royal Statistical Society Series B, 70(3), 495-518.

$\mathrm{Wu}, \mathrm{F}$. (2019). An examination of the effects of consumption expenditures on life satisfaction in Australia. Journal of Happiness Studies. https://doi.org/10.1007/s10902-019-00161-3.

Zhang, J. W., Howell, R. T., \& Caprariello, P. A. (2013). Buying life experiences for the "right" reasons: A validation of the motivations for experiential buying scale. Journal of Happiness Studies, 14, 817-842.

Zhang, J., \& Xiong, Y. (2015). Effects of multifaceted consumption on happiness in life: A case study in Japan based on an integrated approach. International Review of Economics, 62(2), 143-162.

Zimmermann, S. (2014). The pursuit of subjective well-being through specific consumption choice. https:// ssrn.com/abstr act $=2484660$.

Publisher's Note Springer Nature remains neutral with regard to jurisdictional claims in published maps and institutional affiliations. 